\title{
Metabolism of the Phytoalexin Rishitin by Botrytis spp.
}

\author{
By G. D. LYON \\ Scottish Horticultural Research Institute \\ Invergowrie, Dundee $D D_{2}{ }_{5} D A$
}

(Received I7 March 1976)

INTRODUCTION

Wilson (1963) showed that Botrytis cinerea can form a latent infection on tomato plants and it is possible that the phytoalexin rishitin, as an inhibitor of fungal growth, is involved in this relationship. Tomato is known to produce rishitin in response to infection by Phytophthora sp. (Sato et al., 1968), Verticillium sp. (Tjamos \& Smith, 1974) and Fusarium sp. (McCance \& Drysdale, 1975) and might well be expected to produce it in response to other fungi. If growth of the pathogen during latency is prevented by such an inhibitor then it might be broken down for the transition from a quiescent to an aggressive phase to occur. In this paper I describe the effect of B. cinerea, and of Botrytis fabae and Botryotinia narcissicola, which are not pathogenic on tomato, on rishitin in vitro.

\section{METHODS}

Fungi. The isolate of $B$. cinerea Pers. ex Fr. was obtained from tomato (Lycopersicon esculentum Mill) in 1972, that of B. fabae Sard. from field bean (Vicia faba L.) in 1975, and that of Botryotinia narcissicola (Greg.) Buchw. (Imp. St. Botrytis narcissicola Kleb.) from narcissus in 1976; all were maintained on medium X (Last \& Hamley, I956).

Rishitin. This compound was extracted from potato tubers inoculated with Erwinia carotovora var. atroseptica, as described by Lyon (1972).

Incubation of rishitin with fungi. Czapek-Dox liquid medium (Oxoid CM95; $50 \mathrm{ml}$ ) in $250 \mathrm{ml}$ Erlenmeyer flasks was inoculated with $\mathrm{I} \mathrm{ml}$ spore suspension $\left(5 \times 10^{5}\right.$ spores in water plus $2 \%$ ethanol plus $0.04 \%$ Triton X-I00) and shaken at $20{ }^{\circ} \mathrm{C}$. After 7 days' incubation, $250 \mu \mathrm{g}$ rishitin in I $\mathrm{ml}$ ethanol was added to each flask, to give a final concentration of rishitin of $5 \mu \mathrm{g} \mathrm{ml}^{-1}$. Fungal growth was stopped by adding $100 \mathrm{ml}$ methanol, and storing the flask overnight at $4{ }^{\circ} \mathrm{C}$.

Rishitin recovery and estimation. Rishitin was recovered by filtering the culture through Whatman no I filter paper, washing the flask, paper and mycelium with $50 \mathrm{ml}$ methanol, and drying the filtrate by rotary evaporation at $40^{\circ} \mathrm{C}$. The residue was dissolved in $50 \mathrm{ml}$ $60 \%(\mathrm{v} / \mathrm{v})$ methanol which was extracted three times with equal volumes of chloroform. Chloroform phases were combined, dried in vacuo, taken up in chloroform and transferred to I $\mathrm{ml}$ glass vials. The sample was dried in a stream of air, dissolved in $0.25 \mathrm{ml}$ cyclohexane and $\mathrm{I} \mu \mathrm{l}$ of the solution was injected into a gas chromatograph (GC), operated under the following conditions: flame ionization detector; $2 \cdot \mathrm{I} \mathrm{m} \times 4 \mathrm{~mm}$ i.d. glass column packed with $\mathrm{I} \% \mathrm{OV}-\mathrm{I} 7$ on Diatomite CLQ 90 to 100 mesh; oven temperature $190^{\circ} \mathrm{C}$; detector temperature $250{ }^{\circ} \mathrm{C}$; carrier gas (argon) $45 \mathrm{ml} \mathrm{min}{ }^{-1}$; hydrogen $45 \mathrm{ml} \mathrm{min}^{-1}$; air $500 \mathrm{ml} \mathrm{min}^{-1}$. Rishitin (retention time 3. I min) was estimated from the peak area by reference to a calibration curve. An internal standard was not used because possible standards, e.g. methylstearate, had similar retention times to fungal metabolites. 


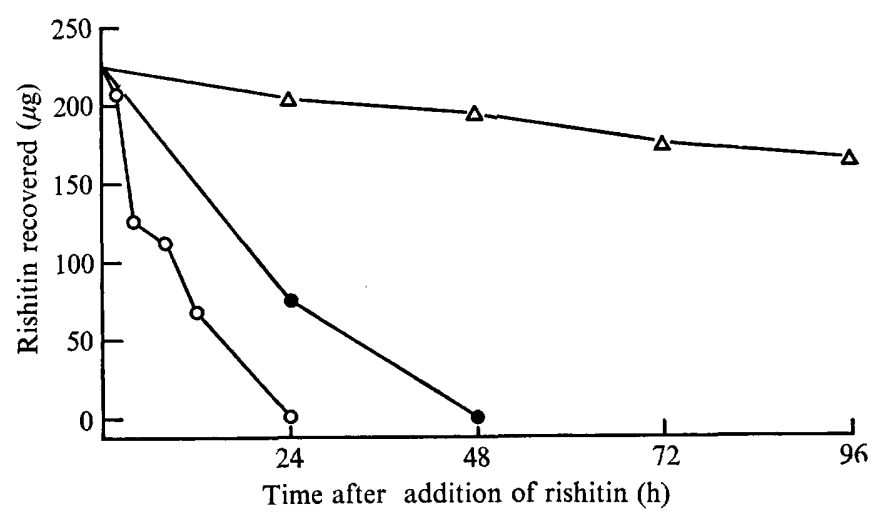

Fig. I. Rishitin recovered from cultures of B. cinerea $(O)$, B. fabae $(0)$ and Botryotinia narcissicola $(\triangle)$, after the addition of $250 \mu \mathrm{g}$ rishitin to 7 -day-old cultures.

\section{RESULTS AND DISCUSSION}

Rishitin was readily metabolized by both $B$. cinerea and $B$. fabae but only slowly by Botryotinia narcissicola (Fig. I). Gas chromatograms did not indicate the presence of any compounds which may have been derived from rishitin during its metabolism. The presence of fungal metabolites (compounds recoverable from cultures to which no rishitin was added) would not have interfered with the detection of a rishitin metabolite had one been present. This suggests that either there were no accumulating products of rishitin metabolism or that the products were not separable by this GC system. The possibility that $B$. fabae metabolizes rishitin to another antifungal compound not detectable by gas chromatography cannot be ruled out. At the time when risihitin was added, flasks contained I65, 105 and 130 mg dry wt mycelium of $B$. cinerea, B. fabae and Botryotinia narcissicola respectively, so the inability of Botryotinia narcissicola to metabolize rishitin rapidly could not be explained in terms of differences in the amounts of mycelium present. After $96 \mathrm{~h}, 98$ to $99 \%$ of added rishitin was recovered from uninoculated flasks.

The ability of $B$. cinerea to metabolize rishitin may partly account for the fact that only a trace of rishitin can be detected in heavily infected tissue (unpublished results). At an early stage in the establishment of a latent infection, there may be only one or a few host cells interacting with a very small quantity of fungal material. It is not yet technically feasible to estimate the concentration of rishitin in such small volumes of tissue.

The results presented here are from initial experiments designed to test Wood's hypothesis (1973) that phytoalexins may well be involved in latency as it is difficult to conceive any other way in which growth of potential pathogens could be stopped.

\section{REFERENCES}

LAST, F. T. \& HAMLeY, R. E. (1956). A local-lesion technique for measuring the infectivity of conidia of Botrytis fabae Sardina. Annals of Applied Biology 44, 410-4I 8.

LYON, G. D. (1972). Occurrence of rishitin and phytuberin in potato tubers inoculated with Erwinia carotovora var. atroseptica. Physiological Plant Pathology 2, 4I 1-4I 6.

McCANCE, D. J. \& Drysdale, R. B. (1975). Production of tomatine and rishitin in tomato plants inoculated with Fusarium oxysporum f. sp. lycopersici. Physiological Plant Pathology 7, 22 I-230.

Sato, N., Tomiyama, K, Katsui, N. \& Masamune, T. (I968). Isolation of rishitin from tomato plants. Annals of the Phytopathological Society of Japan 34, 344-345.

Tuamos, E. C. \& Sмiтh, I. M. (1974). The role of phytoalexins in the resistance of tomato to Verticillium wilt. Physiological Plant Pathology 4, 249-259.

Wilson, A. R. (1963). Some observations on the infection of tomato stems by Botrytis cinerea Fr. Annals of Applied Biology 51, 171 .

Wood, R. K. S. (1973). Hypersensitivity, phytoalexins and disease resistance. Mitteilungen der Biologischen Bundesanstalt für Land- $u$. Forstwirtschaft $\mathbf{1 5 4}, 95-105$. 